\title{
INFLUENCE OF SWIMMING ON WEIGHT CONTROL IN PUBERTAL CHILDREN WITH DOWN SYNDROME
}

\author{
Ioana OPRIŞESCU ${ }^{1}$, Valeria BĂLAN ${ }^{1 *}$ \\ ${ }^{1}$ National University of Physical Education and Sport, Faculty of Kinetotherapy, Bucharest, Romania \\ ${ }^{2}$ National University of Physical Education and Sport, Faculty of Physical Education and Sport, Bucharest, Romania \\ *Corresponding author: valiswim@yahoo.com
}

DOI: $10.35189 /$ iphm.icpesk.2019.26

\begin{abstract}
Overweight is a major health issue of great concern to specialists from all over the world. Recent studies indicate that there are more and more people with overweight or obesity problems. In Romania as well, the data show serious problems related to overweight. A series of disabilities are associated with health issues and overweight. These include people with Down syndrome. Their weight could be controlled through a rigorous exercise programme that should be practiced systematically, with beneficial effects not only on the motor area, but also the functional area. This study was conducted on three pubertal children with Down syndrome - a girl and two boys. The tests were carried out in a specialised clinic and aimed to identify weight problems using anthropometric measurements related to the somatic mass (body weight, skinfolds and body composition). We associated them with physical anthropometric measurements related to body weight, which helped us to better emphasise the effects of physical exercise on body weight. Between the two tests, the three children with Down syndrome participated in swimming lessons as part of the intervention programme. Through these, both the maintenance and improvement of weight-related aspects were pursued, as well as the learning of swimming. Following the processing and interpretation of available data, we have concluded that body weight is an important health criterion for people with Down syndrome to prevent complications of the specific pathology and the occurrence of other comorbidities.
\end{abstract}

Keywords: children with Down syndrome, anthropometric measurements, intervention programme.

\section{Introduction}

Overweight is a major health issue of great concern to specialists all over the world. Recent studies (Fisk, 2017; World Health Organization [WHO], 2018) indicate that there are more and more people with overweight or obesity problems. According to the WHO (2018), in 2016, more than 1.9 billion adults, 18 years and older, were overweight, and of them, over 650 million were obese; also, over 340 million children and teenagers aged between 5 and 19 years were overweight or obese.

In Romania, the data released by the WHO (2013) for 2008 showed serious problems related to overweight ( $51 \%$ of adults over 20 years were overweight, and $19.1 \%$ were obese). At the same time, a report from 2009/2010 highlighted that an important part of teenagers aged 13 years (25\% boys and $15 \%$ girls) were overweight, the ratio being even higher for the children aged 11 years (33\% boys and 19\% girls) (WHO, 2012).

A number of disabilities are conducive to obesity. Thus, the problem of body weight is associated with the main diagnosis in the case of some genetic diseases. Also, the association of overweight in disabled people is a problem that may appear due to sedentariness, the lack of facilities for practicing sport or the lack of trainers to engage them in motor activities.

In recent years, more and more national and international organisations have been trying to find solutions to these problems. People with disabilities are aided by qualified trainers to be active and attend sport activities for both their physical health and psychological satisfaction with practicing sport.

As regards body composition, attention should be paid to all its structures, which can be grouped into relatively fixed components (skeleton, viscera, nerve system and skin) and a number of variable components (muscles, adipose tissue and water) (Cordun, 2011, p. 90). Any individual falls into a standard weight range (normal weight, overweight or obese), according to the assessment and interpretation of the structures mentioned before.

People with Down syndrome also have weight-related problems (Casey, 2013, p. 2; Curat, 2015, p. 148), which can be controlled with the help of a rigorous physical exercise programme and proper diet. The physical exercise programme must be systematically practiced individually or in group, with beneficial effects on the motor and intellectual areas, too. 


\section{Material and Methods}

\section{Subjects}

Our study involved three adolescents with Down syndrome (two boys - M1, M2 and a girl - F 3). They were 12 years old at the initial testing and 13 years old at the final assessment (Table 1), Tanner stage III. We mention that we had the parents' agreement to both involve the children with Down syndrome in the research and interpret and publish the research data. During the research, we respected the provisions of the WMA Declaration of Helsinki (2013) as regards the ethical principles applied to studies performed on human subjects.

Table 1. Subjects involved in the study

\begin{tabular}{|c|c|c|}
\hline & \multicolumn{2}{|c|}{ Age } \\
\hline & Initial Test & Final Test \\
\hline M1 & 12 years and 11 months & 13 years and 11 months \\
\hline M2 & 12 years and 10 months & 13 years and 10 months \\
\hline F3 & 12 years and 11 months & 13 years and 11 months \\
\hline
\end{tabular}

Between the two tests, the three children with Down syndrome participated in swimming lessons as part of the intervention programme. These lessons were aimed at teaching them to swim. At the same time, we wanted swimming to be a means of maintaining and improving their health. The number of classes attended by our subjects ranged between 39 and 46. Subject F3 took part in the largest number of swimming classes (46), and subject M1 took part in the lowest number of swimming lessons.

During our study, we identified several variables that influenced the participation of our subjects in the swimming classes: their compulsory school activity, their parents' availability to bring them to the swimming training, seasonal diseases, other medical problems associated with Down syndrome, etc.

\section{Research tools}

We used anthropometric measurements to assess the somatic composition of our subjects (Cordun, 2009, p. 29): body weight, skinfolds and body composition. In addition, physical anthropometric measurements were used for body weight, which helped us to better highlight the effects of the physical exercise programme practiced by our subjects on their body composition.

- Body weight - is the aggregated weight of the body structures (Cordun, 2011, p. 89); it is assessed using the digital balance and is expressed in kilograms;

- Determination of skinfolds - includes measuring the double layer made by the skin and the subcutaneous adipose tissue. The assessment of skinfolds is necessary to determine body composition; such measurements are performed using a calliper and is expressed in millimetres. The measurement of skinfolds enables to estimate the percentage of body fat. For this research, we measured, on the right side, the tricipital skinfold, subscapularis skinfold and calf skinfold, because they are recommended by Winnick and Short (1999, p. 45) in The Brockport Physical Fitness Test, which is purposely designed to assess people with disabilities.

The assessment of tricipital and calf skinfolds allowed us to estimate body fat percent based on the SlaughterLohman equations (Wood, 2018), which predict body fat in children aged 8-18 years:

- $\quad$ boys: body fat percent $=0.735$ (Triceps + Calf $)+1.0$

- $\quad$ girls: body fat percent $=0.610$ (Triceps + Calf $)+5.1$

- Longitudinal dimensions:

- standing height - is the distance from the vertex to the floor; it is measured with the stadiometer, from the standard standing position, with the head in the Frankfurt plane parallel to the support surface and perpendicularly to the vertical rod of the stadiometer, and is expressed in centimetres;

- Transverse dimensions:

- biacromial diameter (shoulder breadth) - is measured between the acromial points with the compass, the subject being in the standard standing position, and is expressed in centimetres;

- bitrochanteric diameter (hip breadth) - is measured between the trochanteric points with the compass, the subject being in the standing position with heels close together, and is expressed in centimetres. 
- Circular dimensions:

- waist circumference (minimum abdomen circumference) - is measured with the subject in the standing position, using the meter tape positioned at the finest abdomen area or, conventionally, at half the distance between the last rib and ilio-cristalia on the mid-axillary line for the female subject, respectively at the omphalion for male subjects; during measurement, the subject calmly breathes and the dimension is expressed in centimetres;

- fist circumference - is measured using the meter tape positioned at forearm-bone styloid processes and is expressed in centimetres;

- knee circumference - is measured at mid-patella using the meter tape and is expressed in centimetres;

- ankle circumference - is measured horizontally at the narrowest part of the ankle above the tibia sphyrion using the meter tape and is expressed in centimetres.

Using the height and weight, the Body Mass Index (BMI) was calculated based on the following formula: weight $(\mathrm{kg}) /$ height $(\mathrm{m})^{2}$.

The obtained results were compared with the data obtained by other specialists (Cole, Freeman, \& Preece, 1995, pp. 26-28; Fredriks et al., 2005, pp. 808-812) in related tests applied to subjects with Down syndrome of the same age as our subjects. At the same time, we linked our data with the data presented by the Centers for Disease Control and Prevention Growth Charts (CDC, 2000), Growth Charts for Children with Down Syndrome (CDC, 2015), with the Anthropometric Reference Data for Children and Adults (Fryar, Gu, \& Ogden, 2012), Growth Charts for Children with Down Syndrome in the United States (Zemel et al., 2015) and the International Standards for Anthropometric Assessment (International Society for the Advancement of Kinanthropometry, 2001).

The testing of our subjects took place at the "Gral" Medical Centre within the National University of Physical Education and Sport and was performed by a physician and a physiotherapist.

\section{Results}

The assessment results are presented below.

a) Body weight (Figure 1)

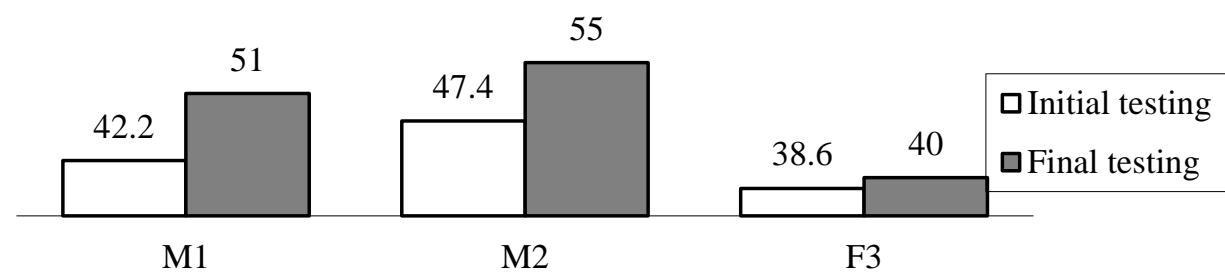

Figure 1. Body weight growth trend

A significant growth in body weight was found for subjects M1 $(8.8 \mathrm{~kg})$ and M2 $(7.6 \mathrm{~kg})$. This could also be explained by the fact that they were pubertal by that time (Tanner stage III).

Table 2. Weight-for-age percentiles compared to the general population growth standards (CDC, 2000)

\begin{tabular}{lcc}
\hline & \multicolumn{2}{c}{ Test } \\
\cline { 2 - 3 } & initial & Final \\
\hline M1 & 36.2 & 52.2 \\
M2 & 61.8 & 68.5 \\
F3 & 17.3 & 11.5 \\
\hline
\end{tabular}

According to the Weight-for-age Growth Charts for Children with Down Syndrome (CDC, 2015) (Table 2), the subjects' weight ranged within the normal values for their age and gender in the initial and final tests, the same conclusion arising from the comparison of relevant values with those of the general population (Table 3). 
Table 3. Weight-for-age percentiles - Growth Charts for Children with Down Syndrome (CDC, 2015)

\begin{tabular}{lcc}
\hline & \multicolumn{2}{c}{ Test } \\
\cline { 2 - 3 } & initial & Final \\
\hline M1 & 50 & $>50$ \\
M2 & $>50$ & $<75$ \\
F3 & $>25$ & 25 \\
\hline
\end{tabular}

b) Determination of skinfolds (Figures 2, 3 and 4):

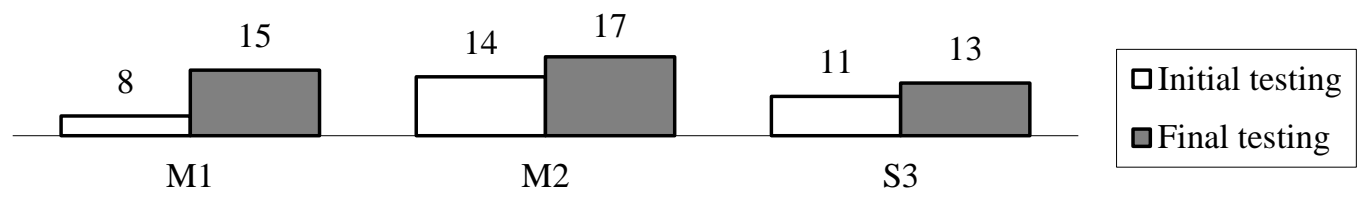

Figure 2. Triceps skinfold thickness trend

The triceps skinfold thickness increased. Medical examination data showed that M1 had a thinner triceps skinfold in the initial test (Figure 2). In the final test, increases of $7 \mathrm{~mm}$ for M1, $1.3 \mathrm{~mm}$ for M2 and $2 \mathrm{~mm}$ for F3 were identified.

According to the Anthropometric Reference Data for Children and Adults (Fryar, Gu, \& Ogden, 2012), the triceps skinfold thickness recorded the following increase: from less than the 25th percentile to the 50th percentile for $\mathrm{M} 1$, from the 50th percentile to the 75 th percentile for $\mathrm{M} 2$ and from less than the 25th percentile to less than the 50th percentile for F3.

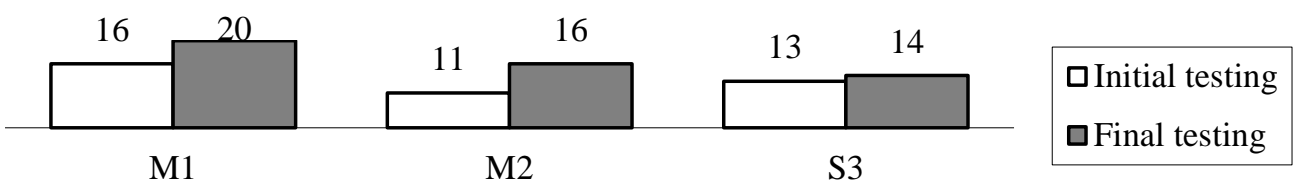

Figure 3. Subscapular skinfold thickness trend

Regarding the subscapular skinfold (Figure 3), the measured increase was $4 \mathrm{~mm}$ for M1, $5 \mathrm{~mm}$ for M2 and 1 $\mathrm{mm}$ for F3. According to the Anthropometric Reference Data for Children and Adults (Fryar, Gu, \& Ogden, 2012), the subscapular skinfold thickness showed the following increase: from the 75 th percentile to the 85 th percentile for M1, constant at the level of the 5th percentile for M2 and constant at the level of less than the 50th percentile for F3.

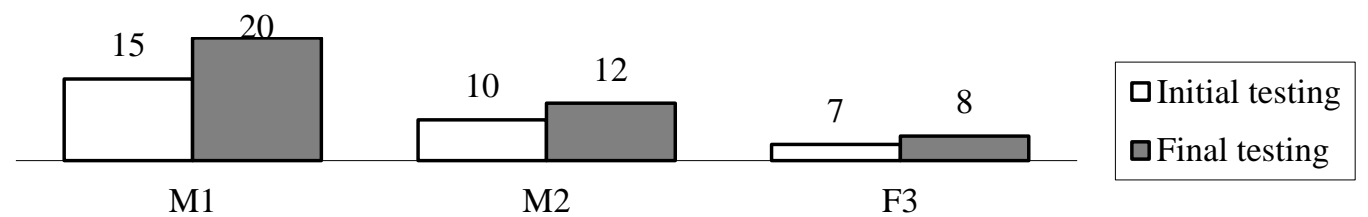

Figure 4. Calf skinfold thickness trend

For the calf skinfold (Figure 4), a significant increase was found for M1 (5 mm), while for M2, the increase was $2 \mathrm{~mm}$, and for F3, $1 \mathrm{~mm}$.

The results obtained by our subjects are shown in Table 4 . 
Table 4. Slaughter-Lohman equations - Body fat percentage

\begin{tabular}{lcc}
\hline & Initial testing & Final testing \\
\cline { 2 - 3 } M1 & 17.90 & 26.72 \\
M2 & 18.64 & 22.31 \\
F3 & 16.08 & 17.91 \\
\hline
\end{tabular}

If we compare our data with the median level estimated by the Slaughter-Lohman equations applied by Freedman, Horlick and Berenson (2013, p. 1419), we can assert that our subjects fall within the limits of the body fat percentage calculated by them: boys, $18.1 \pm 15$, and girls, $24.5 \pm 15$.

c) Longitudinal dimensions (Figure 5)

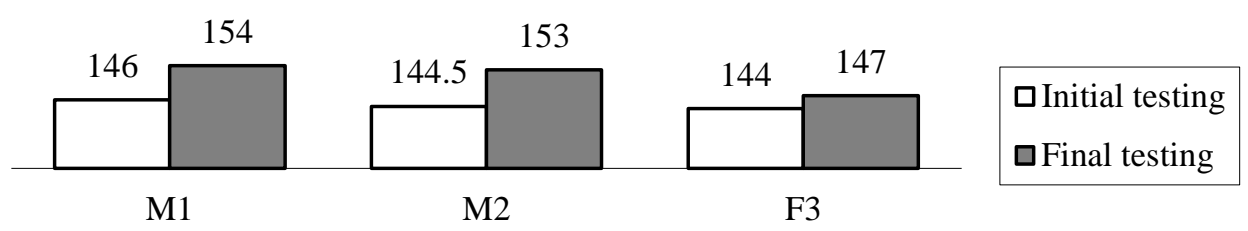

Figure 5. Body height growth trend

The body height of our subjects increased by $8 \mathrm{~cm}$ for M1, $8.5 \mathrm{~cm}$ for M2 and $3 \mathrm{~cm}$ for F3 (Figure 5), the arithmetic mean of these growths being $6.5 \mathrm{~cm}$. Comparing the obtained values with the Growth Charts for Children with Down Syndrome in the United States (Zemel et al., 2015), it can be seen that the initial and final heights of the investigated subjects are above the average height for children with Down syndrome of the same age and gender (the height values being ranged within the 50th and 75 th percentile).

Table 5. Height-for-age percentiles - Growth Charts for Children with Down syndrome (CDC, 2015)

\begin{tabular}{lcc}
\hline & \multicolumn{2}{c}{ Test } \\
\cline { 2 - 3 } M1 & initial & final \\
\cline { 2 - 3 } M2 & $<75 \%$ & $75 \%$ \\
F3 & $50 \%$ & $<75 \%$ \\
\hline
\end{tabular}

d) Transverse dimensions (Figures 6 and 7)

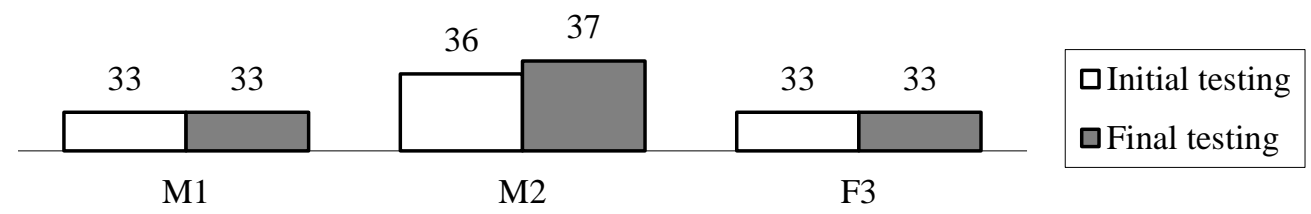

Figure 6. Biacromial diameter (shoulder breadth) growth trend

Biacromial diameter (Figure 6) did not change, except for M2 who recorded a growth of $1 \mathrm{~cm}$. 


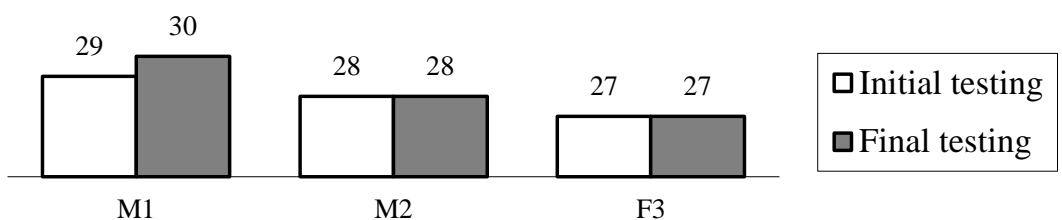

Figure 7. Bitrochanteric diameter (hip breadth) growth trend

The same situation (Figure 7) is recorded for the hip breadth growth, except for M1 who had an improvement of $1 \mathrm{~cm}$.

c) Circular dimensions (Figures 8,9 and 10):

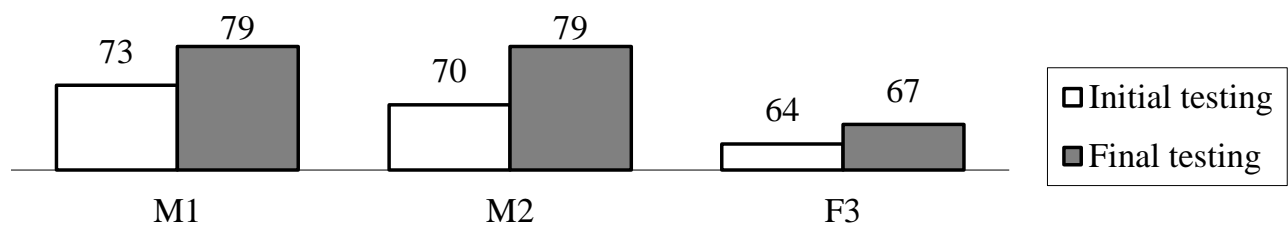

Figure 8. Waist circumference growth trend

The waist circumference (Figure 8) increased by $6 \mathrm{~cm}$ for $\mathrm{M} 1,9 \mathrm{~cm}$ for $\mathrm{M} 2$ and $3 \mathrm{~cm}$ for F3. The growth ranges between the 50th percentile and the $75^{\text {th }}$ percentile in the case of boys and is less for the female subject (F3), ranging around the 25th percentile in the initial test and below the 15th percentile in the final test, compared to the values for the general population (CDC, 2015).

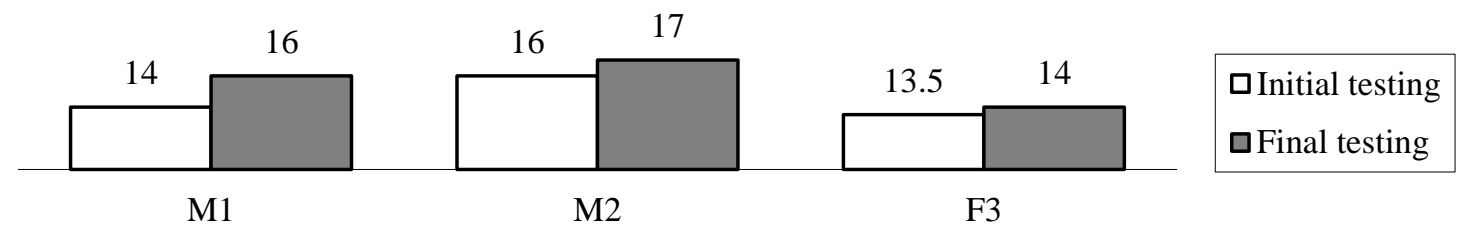

Figure 9. Fist circumference growth trend

The fist circumference values (Figure 9) increased by $2 \mathrm{~cm}$ for M1 and $1 \mathrm{~cm}$ for M2.

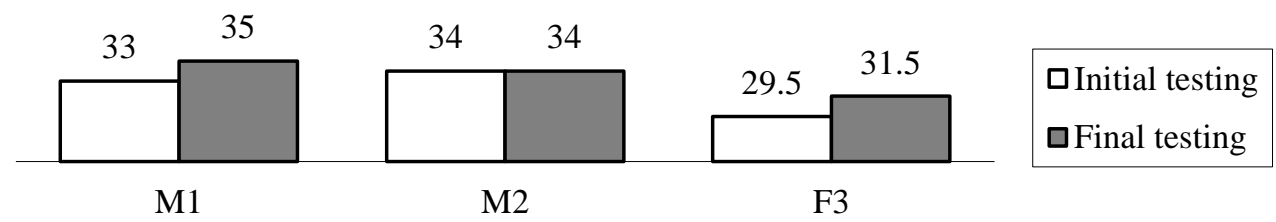

Figure 10. Knee circumference growth trend

The knee circumference (Figure 10) increased by $2 \mathrm{~cm}$ for M1 and F3, but it remained unchanged for M2. 


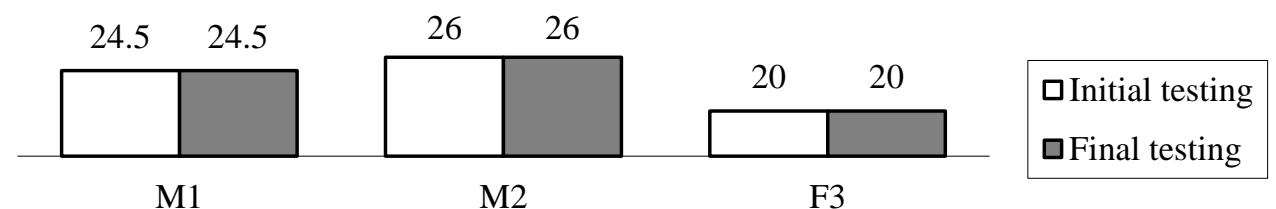

Figure 11. Ankle circumference growth trend

No changes were recorded for the ankle circumference (Figure 11).

Based on the data collected, we computed the Bone Growth Index (Cordun, 2009, p. 118), which showed a strong bone structure in subjects M1 and M2, with values of 49 for M1 and 50.3 for M2. In the case of subject F3, the index was 44.5, showing bones with average development. All values of the Bone Growth Index took into account the results obtained by the subjects in the final test.

e) Body Mass Index - BMI (Figure 12)

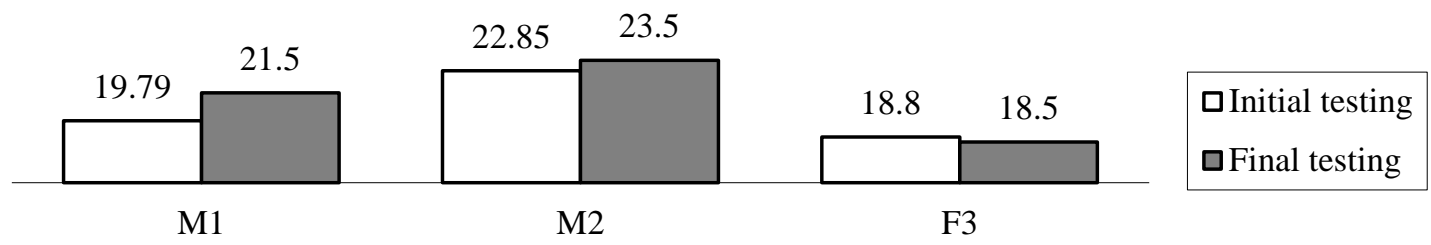

Figure 12. Body Mass Index trend

The Body Mass Index (Figure 12) showed that the values recorded by M1 and F3 in the initial test ranged them in the class of normal-weight children, while the value of M2 ranged him in the class of overweight children, according to both the Growth Charts for Children with Down Syndrome (CDC, 2015) (Table 6) and the BMI-forage general population growth standards (CDC, 2000) (Table 7). For M2, the same result was obtained, namely his classification as an overweight person, also relying on the data indicated as reference by Winnick and Short (1999, p. 45). The situation was similar in the final test.

Table 6. BMI-for-age percentile in comparison with the general population growth standards (CDC, 2000)

\begin{tabular}{lcccc}
\hline & \multicolumn{3}{c}{ Test } \\
\cline { 2 - 5 } & \multicolumn{3}{c}{ Initial } & Final \\
& Percentile & Interpretation & Percentile & Interpretation \\
\hline M1 & 69 & Normal weight & 78 & Normal weight \\
M2 & 89 & Overweight & 89 & Overweight \\
F3 & 49 & Normal weight & 39 & Normal weight \\
\hline
\end{tabular}

Table 7. BMI-for-age for boys and girls with Down syndrome (Zemel et al., 2015)

\begin{tabular}{lcc}
\hline & \multicolumn{2}{c}{ Test } \\
\cline { 2 - 3 } & Initial (percentile) & Final (percentile) \\
\hline M1 & $<50$ & $<50$ \\
M2 & $<75$ & $<75$ \\
F3 & $<25$ & $>10$ \\
\hline
\end{tabular}

All our subjects have BMI values within normal limits, according to the growth charts specific for children with Down syndrome. 


\section{Discussion}

If we relate our data to the analysed international references, we can state that:

1. the predisposition to obesity of people with Down syndrome requires the careful monitoring of the Body Mass Index (Bull \& Committee on Genetics, 2011, p. 400; González-Agüero, Matute-Llorente, Gómez-Cabello, Vicente-Rodríguez, \& Casajús, 2017, p. 100) and waist circumference (Casey, 2013, p. 1). At the same time, they have "unique body morphology and shape" and "body composition other than the healthy children", as well as a typical body fat mass arrangement (Casey, 2013, p. 2; González-Agüero et al., 2017, p. 100).

2. the weight of our subjects was maintained within normal limits in the case of two subjects (M1 and F3). In the case of the third overweight subject (M2), his BMI remained over the 85th percentile, according to the BMIfor-age percentile growth standards for the general population (CDC, 2000). However, M2 falls within normal limits, according to the recent Growth Charts for Children with Down Syndrome developed by Zemel et al. (2015). This difference in the diagnosis of overweight (> the 85th percentile) for children with Down syndrome is observed in several specialised studies. It appears that this depends on the use of specific charts for people with Down syndrome compared to the charts for unchallenged children. Hatch-Stein et al. (2016) concluded that "For children with DS $\geq 10$ years, the CDC BMI growth chart 85 th percentile is a better indicator of excess adiposity than the new DS-specific BMI charts".

\section{Conclusion}

After checking and interpreting our data, we can conclude that:

1. maintaining normal weight is an important objective in pubertal children with Down syndrome to prevent complications of the specific pathology and the occurrence of other comorbidities related to overweight;

2. our assessments showed a correlation between the waist circumference growth and BMI for the overweight subject M2. We did not observe a consistent growth in body fat percent estimated by the Slaughter-Lohman equation. In contrast, subject M1 (normal weight) recorded higher growth in body fat percent. These disparities might be related to both the specific changes occurring in children with Down syndrome during puberty and the limits of anthropometric measurements used to assess body composition.

3. the regular practice of physical activity, particularly swimming, associated with proper diet, are prophylactic measures for reducing overweight especially in children whose growth differs from the norm during the important biological transformation period called puberty. Subjects F3 and M1 regularly attended swimming classes and maintained their body weight within normal limits.

4. preparing national growth charts for children with Down syndrome is a necessity. The monitoring of anthropometric parameters is important in auxological, clinical and practical terms, enabling to identify the existence or early onset of typical co-morbidities for the chromosomal abnormality.

\section{Acknowledgement}

The paper is achieved and published under the aegis of the National University of Physical Education and Sport in Bucharest, as a partner of the programme co-funded by the European Social Fund within the Operational Sectoral Programme for Human Resources Development 2007-2013 through the project Pluri- and interdisciplinarity in doctoral and post-doctoral programmes, Project Code: POSDRU/159/1.5/S/141086, its main beneficiary being the Research Institute for Quality of Life, Romanian Academy.

\section{Authors' Contributions}

Both authors contributed equally to this study and should be considered as main authors.

\section{References}

Bull, M. J., \& Committee on Genetics. (2011). Health supervision for children with Down syndrome. Pediatrics, 128(2), 393-406. https://doi.org/10.1542/peds.2011-1605

Casey, A. F. (2013). Measuring body composition in individuals with intellectual disability: A scoping review. Journal of Obesity, 3, 1-6. https://doi.org/10.1155/2013/628428 
CDC. (2000). Growth charts. Vital Health and Statistics, 11(246). Retrieved from https://www.cdc.gov/growthcharts/cdc_charts.htm

CDC. (2015). Growth Charts for Children with Down Syndrome. Retrieved from https://www.cdc.gov/ncbddd/birthdefects/downsyndrome/growth-charts.html

Cole, T. J., Freeman, J. V., \& Preece, M. A. (1995). Body mass index reference curves for the UK, 1990. Archives of Disease in Childhood, 73(1), 25-29. https://doi.org/10.1136/adc.73.1.25

Cordun, M. (2009). Kinantropometrie [Kinanthropometry]. Bucureşti: CD Press.

Cordun, M. (2011). Bioenergetică şi ergometrie în sport [Bioenergetics and ergometry in sport]. Bucureşti: CD Press.

Curat, G. (2015). Special training. In Activităţi fizice adaptate pentru incluziune socială (pp. 127-130). Bucureşti: Discobolul.

Fisk, M. (2017). Obesity in America compared to Europe. Retrieved from https://www.livestrong.com/article/340188-obesity-in-america-compared-to-europe/

Freedman, D. S., Horlick, M., \& Berenson, G. S. (2013). A comparison of the Slaughter skinfold-thickness equations and BMI in predicting body fatness and cardiovascular disease risk factor levels in children. The American Journal of Clinical Nutrition, 98(6), 1417-1424. https://doi.org/10.3945/ajcn.113.065961

Fredriks, A. M., van Buuren, S., van Heel, W. J., Dijkman-Neerincx, R. H., Verloove-Vanhorick, S. P., \& Wit, J. M. (2005). Nationwide age references for sitting height, leg length, and sitting height/height ratio, and their diagnostic value for disproportionate growth disorders. Archives of Disease in Childhood, 90, 807-812. https://doi.org/10.1136/adc.2004.050799

Fryar, C. D., Gu, Q., \& Ogden, C. L. (2012). Anthropometric reference data for children and adults: United States, 2007-2010. Vital Health Statistics, 11(252), 1-40. Retrieved from https://www.cdc.gov/nchs/data/series/sr_11/sr11_252.pdf

González-Agüero, A., Matute-Llorente, A., Gómez-Cabello, A., Vicente-Rodríguez, G., \& Casajús, J. A. (2017). Percentage of body fat in adolescents with Down syndrome: Estimation from skinfolds. Disability and Health Journal, 10(1), 100-104. https://doi.org/10.1016/j.dhjo.2016.05.013

Hatch-Stein, J. A., Zemel, B. S., Prasad, D., Halkwarf, H. J., Pipan, M., Magge, S. N., \& Kelly, A. (2016). Body composition and BMI growth charts in children with Down syndrome. Pediatrics, 138(4): e20160541. https://doi.org/10.1542/peds.2016-0541

International Society for the Advancement of Kinanthropometry. (2001). International standards for anthropometric assessment. Underdale, SA, Australia: ISAK.

Winnick, J. P., \& Short, F. X. (1999). The Brockport Physical Fitness Test Manual. Champaign, IL, Human Kinetics.

Wood, R. (2018). Slaughter-Lohman body fat equations. Topend Sports Website, May 2018. Retrieved from https://www.topendsports.com/testing/bodyfat-equation-slaughter-lohman.htm

WHO. (2013). Nutrition, physical activity and obesity - Romania. Monitoring and surveillance: Overweight and obesity in three age groups. Retrieved from http://www.euro.who.int/_data/assets/pdf_file/0014/243320/Romania-WHO-Country-Profile.pdf

WHO. (2018). Obesity and overweight. Retrieved from https://www.who.int/news-room/fact-sheets/detail/obesityand-overweight

WHO. (2012). Social determinants of health and well-being among young people: Health Behaviour in Schoolaged Children (HBSC) study: International report from the 2009/2010 survey. Copenhagen. Retrieved from http://www.euro.who.int/_data/assets/pdf_file/0003/163857/Socialdeterminants-of-health-and-well-beingamong-young-people.pdf

Zemel, B. S., Pipan, M., Stallings, V. A., Hall, W., Schadt, K., Freedman, D. S., \& Thorpe, P. (2015). Growth Charts for Children with Down Syndrome in the United States. Pediatrics, 136(5): e1204-1211. https://doi.org/10.1542/peds.2015-1652 